\title{
EL SEGUNDO OFICIO DEL ESCRITOR. PHOTO-PHOTO, DE MARIE NIMIER, O LA TEXTUALIZACIÓN DE LA POSE AUTORIAL
}

\author{
Meri TORRAS FRANCÈS \\ Universitat Autònoma de Barcelona
}

\begin{abstract}
Il faut parfois du temps entre la découverte d'une photo et le moment où l'on accepte l'image qu'elle donne de vous. À force de rester des heures devant du papier blanc on se perd un peu de vue, on le sait, on se dit que ça viendra, qu'on s'habituera, mais en l'occurrence, l'étincelle ne se produit pas. Au contraire, à mesure que les jours passent, la sensation d'étrangeté s'accentue.
\end{abstract}

Marie Nimier, Photo-Photo

I

$\mathrm{E}$ 1 miércoles primero de junio de 1932 un salón de belleza abre sus puertas en el número 6 de la calle de Miromesnil, de París, un hecho que no tendría nada de relevante para el tema de este artículo si no fuera porque la mujer que regentaba el establecimiento no era otra que Colette. La autora de la famosa saga de Claudine lanzaba así su sello publicitario en Productos de Belleza y elegía una imagen que unía el perfil inconfundible de su cabeza, su caligrafía y su firma.

Esta imagen pone en evidencia que no estamos, pues, ante un intento de provisión económica ajeno a su labor literaria, al contrario: es desde su ser escritora que Colette irrumpe en el espacio de la cosmética parisina. Una irrupción relativa, cabe admitir, dado que la autora de Chérie o de Sido había practicado también el oficio de periodista y de artista de music-hall, además de haber rubricado por entonces de cuerpo y letra varias publicidades de productos tan diversos como firmas de moda, bebidas, coches o tabaco.

Según cita Frédéric Maget ${ }^{1}$, a todos aquellos y todas aquellas que se mostraron sorprendidos de que una autora tan reputada pretendiera ocuparse profesionalmente de vender productos para el cuerpo, incluso poniendo su propio cuerpo en escena, Colette respondió pocos meses después, desde las páginas del Vogue y no sin ironía cómplice:

Non sans sourire je regarde dans mon passé, et je me souviens d'un temps où l'on s'étonna que d'oisive et docile petite épouse je devinsse officiellement écrivain. À peine affermissais-je mon petit renom d'auteur, que je «montai sur les planches», comme on disait autrefois. Ainsi je passai mime, et un peu danseuse, et un peu acrobate et j'encourus, déjà, sévères critiques [...]. Six ans plus tard, je m'amendais au point de diriger la partie littéraire d'un grand quotidien, et d'y tenir la rubrique de la critique théâtrale, sans pour cela négliger le roman. Romans, volumes de nouvelles [...] re-romans, re-volumes de nouvelles... Entre-temps, le reportage me servait de récréation [...] Voilà qu'à l'âge où d'autres finissent, je prétends recommencer! Mon cas est grave. (Colette, 2014: 8) ${ }^{2}$

Y sin el bálsamo de la ironía, Colette desafiaba a aquellos y aquellas que importunaban con críticas absurdas su quehacer con una pregunta directa, binaria, una diatriba que convirtió en el slogan publicitario de su firma, entendida ya en un sentido más amplio que la de sello comercial, puesto que afectaba por completo a su firma de autora:

\footnotetext{
1 Maget se ha ocupado de recopilar todos estos textos en el volumen que otorga parte del título a este artículo, entresacado -como inmediatamente se verá- de la propia Colette: Le second métier de l'écrivain.

${ }^{2}$ «No sin sonreír miro en mi pasado, y me acuerdo de un tiempo en que se sorprendieron que de ociosa y dócil mujercita me convirtiera oficialmente en escritor. A penas consolidaba mi modesta fama de autor, que subí "a las tablas", como se decía antaño. Así fui mimo, un poco bailarina, y un poco acróbata y me enfrenté ya a críticas severas [...]. Seis años más tarde, enmendé hasta el punto de dirigir la sección literaria de un gran diario, y de responsabilizarme de la sección de crítica teatral, sin por ello abandonar la novela. Novelas, volúmenes de relatos [...] re-novela, re-volúmenes de relatos... Mientras tanto, el reportaje me servía de distracción [...] he aquí que a la edad en que otros acaban yo pretendo recomenzar! Mi caso es grave». La traducción es mía.
} 


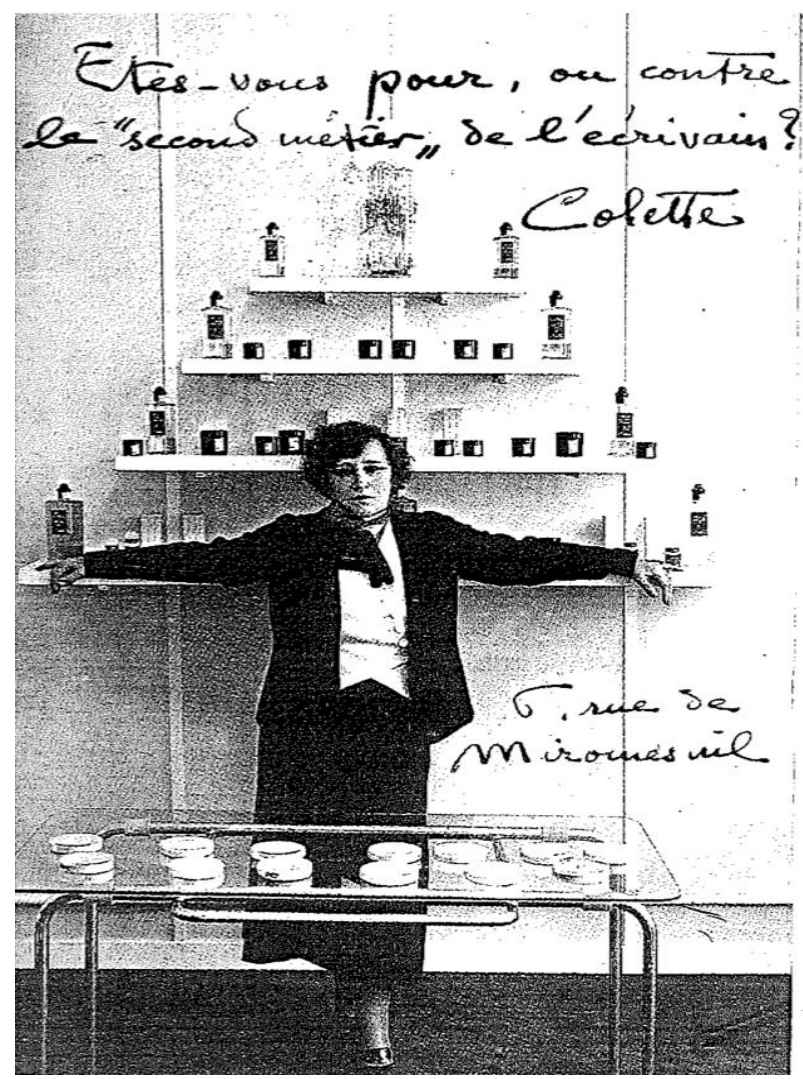

«¿Está usted a favor o en contra del segundo oficio del escritor?».

He aquí la cuestión.

II

Marie Nimier, autora de la novela en la que me centraré en este texto, empezó en el teatro y en el canto, actividades que de algún modo arrastró (o le arrastraron) a su primer oficio de escritora, puesto que es autora de textos dramáticos y letras de canciones, así como de una docena de novelas, algunas de tintes autobiográficos, como La reina de la noche, que le valió el premio Médicis, y que discurre entorno de la figura de su padre, el también escritor Roger Nimier.

Photo-Photo se publicó en 2012 y no es un texto del todo ajeno a los motivos autográficos en tanto que parte de la novelización de una anécdota que le sucedió a Nimier, de modo que la protagonista del relato es una escritora, una especie de alter ego ficcional de la autora y algunos de sus coprotagonistas son seres reales ( si es que este sintagma tiene algún sentido) o sujetos a quienes atribuimos una existencia jurídica documentada, como por ejemplo los artistas Édouard Levé y Karl Lagerfeld.

Photo-Photo. La duplicación del título es la clave, el avance de un juego de desdoblamientos que cruza la novela a partir de la anécdota real a la que he hecho referencia. En 2008, la revista Paris-Match encargó al Rey de la Moda, el artista de origen alemán Karl Lagerfeld, que realizara una fotografía de nueve escritores, entre ellos Marie Nimier. La sesión fotográfica y sobre todo su preparación, se narran morosa y minuciosamente a lo largo del primer capítulo, imprimiendo en el texto un ritmo y una tensión que lo cruzará por entero: la dinámica ausencia versus presencia, el 
motor mismo de cualquier representación, la de la fotografía sin duda, pero también la del lenguaje y, por lo tanto, la de la escritura. Aquí descansa, como trataré de mostrar, mi propuesta interpretativa.

Pero avancemos poco a poco con Nimier, para desgranar como, con fines publicitarios o no, con intención, voluntad y/o gusto, o sin ninguna de esas cosas, un segundo oficio se impone a los escritores y las escritoras en la actualidad: el posar ante los objetivos fotográficos, saber construirse en los medios, mostrarse de determinada manera en la esfera pública parece pues imprescindible para llamarse escritor o para, como puntualiza José-Luís Diaz, hacerse llamar escritor. Ser reconocido como tal.

¿Cómo se enfrenta el escritor - una escritora, en nuestro caso- a la imposición de este segundo oficio? ¿Cómo (se) gestiona el sujeto (en) su duplicado autorial? Éstas, entre otras, son algunas de las cuestiones por las que discurre Photo-Photo. Mi hipótesis de lectura es que ante la desposesión que supone la fotografía inicial del relato, la protagonista escritora se reposee de la única manera que sabe y puede, a través de la escritura de una novela que se va haciendo autoreflexivamente ante nuestros ojos. ¿Implica esto que Marie Nimier se venga y recupera su cuerpo, el único en el que puede reconocerse como escritora, su corpus ficcional? No me atrevería a afirmarlo, no obstante, algo de eso parece acontecer en el laberinto de espejos que confiere el relato.

\section{La pose que desposee o la muerte sin cadáver}

El proceso al que el equipo de Lagerfeld somete el cuerpo de la escritora en el estudio de la parisina calle de Lille avanza lentamente a lo largo del primer capítulo de la novela y da cuenta de un paulatino extrañamiento de sí, que irá embargando la protagonista. En La cámara lúcida, ya Roland Barthes advierte que «la Fotografía es el advenimiento de yo mismo como otro» (Barthes, 2004: 40), una objetualización que termina en el producto final (la materialización de la foto) pero que empieza antes, ya en la pose o, en la novela de Nimier, en la preparación de la pose. «Ante el objetivo soy a la vez: aquel que creo ser, aquel que quisiera que crean, aquel que el fotógrafo cree que soy y aquel de quien se sirve para exhibir su arte. Dicho de otro modo, una acción curiosa: no ceso de imitarme [...]» (Barthes, 2004: 41-42).

En tanto que escritora, para la protagonista, la pose no acontece únicamente en el momento en que se halla ante el objetivo de la cámara: la postura autorial, para decirlo con Jerome Meizôz, se construye como puesta en escena mediática desde cuya recreación el escritor/la escritora toma la posición reconocida de autor (un ethos), a la vez que se esfuerza en imprimir su singularidad, su condición de único (a la que hoy en día cualquier autor que se precie aún no puede renunciar). He aquí una de las paradojas que constituye, en parte, el ethos autorial: quiero que me reconozcan semejante a otros escritores pero único. Una inscripción discursiva de autor demanda una respuesta de reconocimiento y desconocimiento: sí, es un autor (porque mira, gesticula, habla, viste, piensa... como un autor) pero no se parece a nadie, es único. Tal vez por ello y ante la sorpresa de la protagonista, Karl Lagerfeld opta por fotografiar los nueve escritores por separado y montarlos digitalmente como si compartieran un mismo lugar al mismo tiempo. 
Si Barthes reconoce en la fotografía un carácter espectral «por ese algo terrible que hay en toda fotografía: el retorno de lo muerto»(Barthes, 2004: 36), Nimier le dará la vuelta en este episodio para convertirla en la desaparición de lo vivo:

Oui, quelque chose en moi se laissait embaumer, pour préparer le passage de mon être de trois à deux dimensions. Un déclic, et clac! dans la boîte, comme des autres écrivains qui m'avaient précédée. Une mort sans cadavre, pensai-je, sans pleurs ni couronnes, sans compassion, sans rien. Je continuerais à vivre, à rire, à manger, mais une partie de moi resterait figée dans l'immense bibliothèque. (Nimier, 2012: 30$)^{3}$

Esta muerte sin cadáver será repetida, parafraseada, en la novela de varias maneras, de entrada con la frase que le deja caer Lagerfeld en el momento previo a fotografiarla: «Vous savez que vous avez un sosie?» (Nimier, 2012: 36) «¿Sabía usted que tiene un doble?», el rastro y el rastreo de esa doble, Frédérika, recorrerá el resto del relato. Hay otras formas de rescribir la duplicación en el texto: por ejemplo, el episodio del gato blanco de la vecina que la protagonista ve muerto en la carretera, con un hilo de sangre y formando un ángulo particular con la línea de la calzada, y luego el cadáver desaparece y el gato sigue vivo en casa de la vecina. Otro modo será cuando, tras la sesión, en la Gare de Saint-Lazare, en busca del tren que la devolverá a su casa en Normandía, la escritora se enfrenta a las fotografías siempre escalofriantes de personas desaparecidas. Poco tiempo después, cuando contemple la fotografía en el Paris-Match afirmará:

Pourquoi nous a-t-on réunis sur cette page, la page numéro 13 (ou plutôt que réunis, collés comme les vignettes d'un bulletin de commande)? Qu'avons-nous en commun, et si nous ne partageons pas les mêmes ombres, la même lumière, quel est le sens de cette mise en scène?

Voilà ce que la photo révèle, bien malgré elle : nous avons tous écrit. Nous connaissons tous ce silence-là, cette façon d'être, et de ne pas être à la fois. De déserter un corps pour habiter un texte, comme si nous étions à notre tour portés disparus. (Nimier, 2012: 48-49) ${ }^{4}$

Más adelante habrá que volver a esta constatación, por el momento me voy a detener en el hecho de que esta fotografía contradice uno de los axiomas que Barthes atribuye al medio en su ensayo. Su noema: «Esto ha sido» (Barthes, 2004: 121).

\section{Lo que no tuvo lugar o el lugar es el texto}

En efecto, a tenor de esta reflexión la foto se convierte en un testimonio de lo que jamás sucedió - ¿es por ello necesariamente un testimonio falso?- e instala un cuerpo de autor en un lugar en el que nunca estuvo, formando parte de una imagen que jamás pudo ser vista porque literalmente no tuvo lugar: «La malaise qui s’en dégage peut se résumer en une phrase : nous sommes là assis,

\footnotetext{
${ }^{3}$ «Sí, algo en mí se dejaba embalsamar, para preparar el paso de mi ser de tres a dos dimensiones. Un clic, y zas! en la caja, como los otros escritores que me habían precedido. Una muerte sin cadáver, pensé, sin llantos ni coronas, sin compasión, sin nada. Seguiría viviendo, riendo, comiendo, pero una parte de mí se quedaría fijada en la inmensa biblioteca».

4 «¿Por qué se nos había reunido en esta página, la número trece (o mejor dicho, pegado como las viñetas de un catálogo)? ¿Qué tenemos en común, y si no compartimos las mismas sombras, la misma luz, cuál es el sentido de este teatro escénico? He aquí lo que la foto revela muy a su pesar: todos hemos escrito. Conocemos todos este silencio, esta manera de ser, y de no ser a la vez. De desertar un cuerpo para habitar un texto, como si nosotros también estuviéramos desaparecidos».
} 
tous les neuf, comme si nous étions ensemble. Mais nous ne sommes pas ensemble» (Nimier, 2012: $47)^{5}$.

Cabe entender, entonces, con la protagonista, que la fotografía de Lagerfeld materializa con su propio lenguaje el proceso de escritura, la creación de un mundo que no (necesariamente) tuvo lugar. Un autor lo es por su capacidad de «desertar de un cuerpo y habitar un texto» en la suplantación de otra representación, la de las palabras, que no solo no son las cosas sino que nos condenan a no poder estar nunca en contacto directo con las cosas.

En su Iconographie de l'auteur, Ferrari y Nancy, aplican esta tensión al binomio autor-obra o, si prefieren, corpus-cuerpo: «Jamás nadie podrá ver en un retrato - pintura, diseño, foto, retrato escrito o musicado, biografía histórica o novelada- el rostro de un autor. Pero jamás nadie podrá mirar el retrato del signatario de una obra sin escrutar allí la presencia del autor» (Nancy y Ferrari, 2005: 13$)^{6}$.

El autor vive como la ausencia presente y la presencia ausente en aquello que lo representa y aquello que representa, la obra, las palabras, como Nimier está y no está en su novela Photo-Photo o en la fotografía de Lagerfeld. Al contemplar su cuerpo en las páginas satinadas de la revista, la escritora protagonista no se reconoce: «En remontant au-delà du manteau vert, il y a un visage qui pourrait être le mien, s'il ne manquait quelque chose au niveau des yeux, la cicatrice peut-être, oui, à bien y regarder, manque aussi, plus bas, la marque de varicelle» (Nimier, 2012: 47)7 .

Esta impresión de ser el objeto de una impostura atraviesa el autor/la autora fotografiado/a, no únicamente por razones personales. Como revelan los conceptos de ethos, de Dominique Maingueneau, o de posture, de Jerome Meizôz, hay una construcción retórica, social y cultural de la imagen de escritor con la que la protagonista confiesa que debe medirse cada vez que publica un libro y es requerida por los medios. A pesar de las diferencias de género sexual que constata cruzan las imágenes de autores y autoras, hay una serie de atributos compartidos en esta iconografía.

Primero, los autores son seres-tronco desprovistos de la mitad inferior del cuerpo:

La partie inférieure de son corps est rarement exposée, mais à bien y réfléchir, a-t-il seulement une partie inférieure?

Un bassin? Des cuisses? Des mollets?

Un pli du genou?

Une malléole?

Dans le doute, on s'abstient. On montre le haut. On le met en valeur. En bas, il doit y avoir vaguement quelque chose, mais quoi? (Nimier, 2012: 51$)^{8}$

\footnotetext{
5 «El malestar que se desprende de ello puede resumirse en una frase: estamos aquí sentados, los nueve, como si estuviéramos juntos. Pero no estamos juntos».

${ }^{6}$ Debo la cita (y su traducción) a Aina Pérez Fontdevila.

${ }^{7}$ «Subiendo por encima del abrigo verde, hay un rostro que podría ser el mío, si no faltara alguna cosa en la zona de los ojos, la cicatriz tal vez, sí, si se mira mejor, falta también más abajo, la marca de varicela».

${ }^{8}$ «La parte inferior de su cuerpo raramente se expone, pero pensándolo mejor, ¿tiene realmente una parte inferior?

¿Una pelvis? ¿Muslos? ¿Gemelos?

¿Un pliegue de la rodilla?

¿Un tobillo?

En la duda, nos abstenemos. Mostramos la parte de arriba. Le sacamos partido. Y abajo debe de haber un algo, pero ¿qué?».
} 
Segundo, se pueden distinguir dos tipos de escritores: los sedentarios, cuyo hábitat es el escritorio, y los escritores viajeros, que esos sí suelen tener piernas, porque las usan para irse a países distintos, a festivales, certámenes, encuentros, y son fotografiados «preferentemente al lado del mar», puntualiza Nimier. En todo caso las fotos de los escritores viajeros tienen suelo.

Tercero, los sedentarios no, esos parecen flotar hechos un medio cuerpo, acompañados de ciertos complementos: «[O]n se contentera le plus souvent de leur visage (parfois armé d'une cigarette, mais de moins en moins) et de leurs mains (parfois armées d'un stylo, mais de moins en moins)» (Nimier, 2012: 52) ${ }^{9}$

Cuarta y última observación: «Signe distinctif toutes catégories confondues, hommes, femmes, sédentaires ou voyageurs: l'intelligence du regard. Le fameux regard qui frise celui qui en dit long. Les jambes: coucouche panier» (Nimier, 2012: 52) ${ }^{10}$.

Quisiera ahora poner en contraste este planteamiento de Nimier que entiende la fotografía del autor como una imagen sostenida por una red de tópicos, codificados, reconocibles, con la idea de Ferrari y Nancy en principio aparentemente contraria, de la fotografía del autor como opuesta al cliché:

Cuando, por la imagen, el carácter de un sujeto ha sido percibido y así, en lugar de encerrarlo en un cliché, lo abre a las fuerzas que constituyen su naturaleza enigmática, es posible instaurar una vía de comunicación, un pasaje de la obra al autor y, recíprocamente, del autor a la obra. La imagen deviene algo así como una puerta de entrada o una llave de legibilidad que permite que sea visible, en los rasgos de un sujeto, y en sus detalles mismos, el carácter de una obra. Ese sujeto es el autor, el sujeto-autor, mientras que la imagen es el medium entre el sujeto y la obra. (Ferrari y Nancy, 2005) $)^{11}$

Cierto es que el cuando inicial de la cita circunscribe las afirmaciones que la conforman a que se cumpla la primera de ellas. No obstante, podemos preguntarnos a qué se refieren los dos filósofos con naturaleza enigmática y si ésta es condición sine qua non de un sujeto-autor. Ferrari y Nancy presentan la imagen del autor como una puerta de entrada/salida a la obra, una especie de clave reveladora parece que por preservar un enigma (parece también) que necesario. De ahí que la tilden de medium.

A juicio de Ferrari y Nancy entiendo, pues, que el cuerpo del autor forma parte de la fisonomía que damos a las palabras cuando leemos (yo añadiría determinados) corpus, puesto que no todos los textos tienen autor. De la indisociabilidad entre autor y obra, incluso de la necesidad de buscar y encontrar al autor cuando leemos habló ya el gran parricida del congreso, Roland Barthes, en El placer del texto, como ya han referido desde México Adriana de Teresa o, desde Francia, Alain Brunn. Les recuerdo la cita de Barthes:

\footnotetext{
9 «Nos conformaremos la mayoría de los casos con su rostro (a veces armado con un cigarrillo, pero cada vez menos) y con sus manos (a veces armadas de una pluma, pero cada vez menos)».

10 «Signo distintivo sin distinción de categorías, hombres, mujeres, sedentarios o viajeros : la inteligencia de la mirada. La famosa mirada que roza la que todo lo dice.

Las piernas: ¡al rincón!».

${ }^{11}$ Nuevamente, debo la cita (y su traducción) a Aina Pérez Fontdevila.
} 
Como institución el autor está muerto: su persona civil, pasional, biográfica, ha desaparecido [...] Pero en el texto, de cierta manera, yo deseo al autor: tengo necesidad de su figura (que no es ni su representación ni su proyección), tanto como él tiene necesidad de la mía (salvo si sólo murmura). (Barthes, 1973: 46)

Yo deseo al autor.

Je désire l'auteur.

Más cerca de Barthes y las ilógicas del deseo, enfocándolo más bien como una exposición que como veladura enigmática, la autora protagonista de Photo-Photo, reconoce en la fotografía de Lagerfeld la irrupción de una pulsión escópica pornográfica. El símil es suyo:

Un système dont l'efficacité rejoint celle des images pornographiques, où ce qui est donné à voir est rigoureusement orchestré, codifié, dans un souci pressant d'utilité. De rendu. De résultat. Les seins, le sperme, la queue, voilà ce qui saute aux yeux, comme sautent aux yeux la frange, le col, la cigarette. Rien ne vient troubler l'évidence du simulacre. (Nimier, 2012: 52) ${ }^{12}$

Lamentablemente el espacio me impide referirme a la otra fotografía -otra duplicación de la primera- con la que Nimier cierra la novela. Entretanto Photo-Photo con este juego de duplicados que la atraviesa desde el título hasta el final nos ha dado el cuerpo de la autora: su corpus. El texto. La obra. Este es su único retrato im/posible:

Les mots parlent pour moi, certes, mais pour un moi flottant, protéiforme, une espèce de monstre aux petites mains potelées capable aussi bien des pensées les plus ignobles que des sentiments les plus raffinés. N'est-ce pas cette invisibilité que je recherche, ou plutôt que cette invisibilité, cette façon de me débarrasser des attributs de genre, de forme, de densité, pour endosser plus de personnages qu'aucun comédien ne pourra jamais en interpréter au cours de sa carrière? Certains jours, $\mathrm{j}$ 'ai l'impressions que le langage lui-même dicte le texte, le langage avec ses règles, son rythme, son histoire, ses contraintes, ses failles, et qui saura photographier le langage ? (Nimier, 2012: 49-50) ${ }^{13}$

\section{Referencias bibliográficas}

BARTHES, Roland (1973): Le plaisir du texte. París, Seuil. (2004): La cámara lúcida. Nota sobre la fotografía. Trad. de Joaquim Sala-Sanahuja. Barcelona, Ediciones Paidós.

BRUNN, Alain (2001): L'auteur. París, Flammarion.

\footnotetext{
12 «Un sistema cuya eficacia se parece a la de las imágenes pornográficas, donde lo que se ofrece a la mirada está rigurosamente orquestado, codificado, con un apremio de utilidad. De rentabilidad. De resultado. Los senos, el esperma, la cola, he aquí lo que salta a la vista, como saltan a la vista el flequillo, el cuello de la camisa, el cigarrillo. Nada viene a perturbar la evidencia del simulacro».

13 «Las palabras hablan por mí, está claro, pero por un yo flotante, proteiforme, una especie de monstruo de manitas rechonchas capaz tanto de pensamientos innobles como de los sentimientos más refinados. ¿No será esta invisibilidad la que yo busco, o mejor que esta invisibilidad, esta manera de desembarazarme de los atributos de género, de forma, de densidad, para cargarme con más personajes que cualquier otro actor no podrá jamás interpretar a lo largo de su carrera? Algunos días tengo la impresión de que el lenguaje mismo dicta el texto, el lenguaje con sus normas, su ritmo, su historia, sus constreñimientos, sus brechas, y ¿quién sabrá fotografiar el lenguaje?».
} 
92 Tropelías. Revista de Teoría de la Literatura y Literatura Comparada, 24 (2015)

Meri Torras Francès

De Terea OchoA, Adriana (2010): «La función del autor en la circulación literaria», en A. DE TERESA OCHOA, coord., Circulaciones: trayectorias del texto literario. México, Bonilla Artigas editores.

Colette, Sidonie-Gabrielle (2014): Le second métier de l'écrivain, en F. MAGET, ed. París, L'Herne.

FERRARI, Federico y NANCY, Jean-Luc (2005): Iconographie de l'auteur. París, Galilée.

NiMIER, Marie (2012): Photo-photo. París, Gallimard. 